\title{
SEABED INSTABILITY AROUND CAISSON BREAKWATERS
}

\author{
Gerardo Duran, UNAM, Mexico, GDuranV@iingen.unam.mx \\ Juan M. Mayoral, UNAM, Mexico, JMayoralV@iingen.unam.mx \\ Edgar Mendoza, UNAM, Mexico, EMendozaB@iingen.unam.mx \\ Rodolfo Silva, UNAM, Mexico, RSilvaC@iingen.unam.mx
}

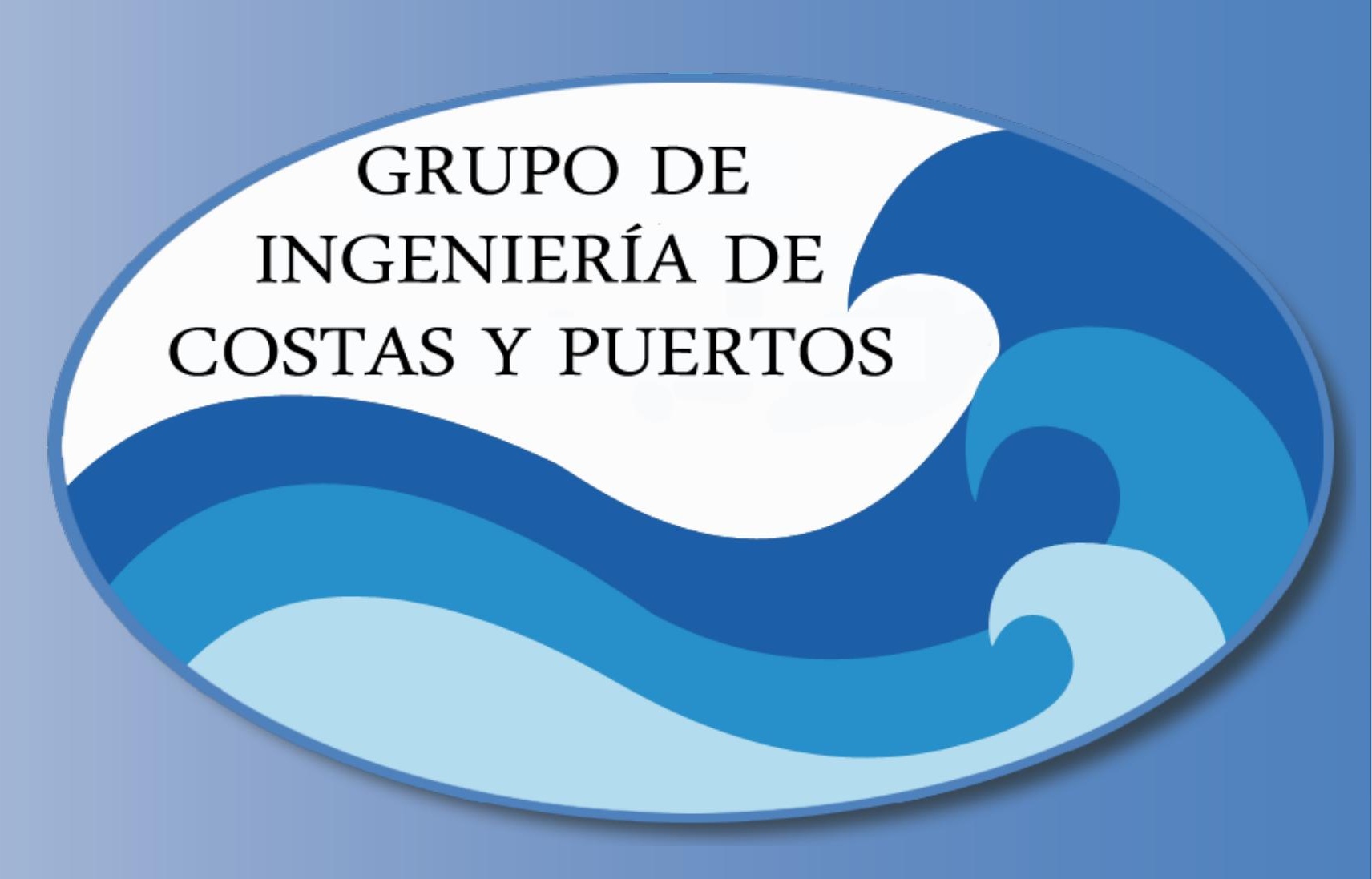

\section{Introduction}

Considering that the vast majority of maritime structures are built directly on the seabed, the characteristics of the seabed significantly influence their behavior. Among all possible causes of instability, this study deals only with those associated with liquefaction failure, such as pore pressure. This poster presents pore pressure simulations of the seabed-structure system due to cyclic shear stresses, generated by regular waves. The modelled seabed is composed of four clay layers and one silty sand layer. The system considered is that of a Seabed-Structure, which is impacted cyclicly by regular waves.

For the numerical model, the cross section of the system in a 2D regular grid domain was discretized, which solves the Biot's consolidation equations via a lagrangian analysis based on an explicit finite difference method. This model is coupled with two constitutive models: Mohr-Coulomb and Finn-Byrne.

\section{Motivation}

There are many incidents of seabed failure recorded in the literature, a large number of which are related to liquefaction. The most representative events that motivated this research are:

- Caisson failure induced by liquefaction: Barcelona Harbour, Spain, 2001.

-The Usumacinta Oil Platform settling: Tabasco, Mexico, 2007.

\section{Proposed approach}

-The design conditions of the caisson dike were considered as those used at Barcelona Harbour,. The dimensions of the caisson, as well as the wave pressures for this study were computed by means of Goda's formulation (1973).

-The design of the embankment was made using the Brebner and Donnelly formulation (1962).

-The seabed stratigraphy was obtained through the Solum company report (1990), at the coordinates UTM $(530839,2080001) 15 Q$.

-The meteorological variables, including wave climate, were taken from Ruiz, et al, 2008.

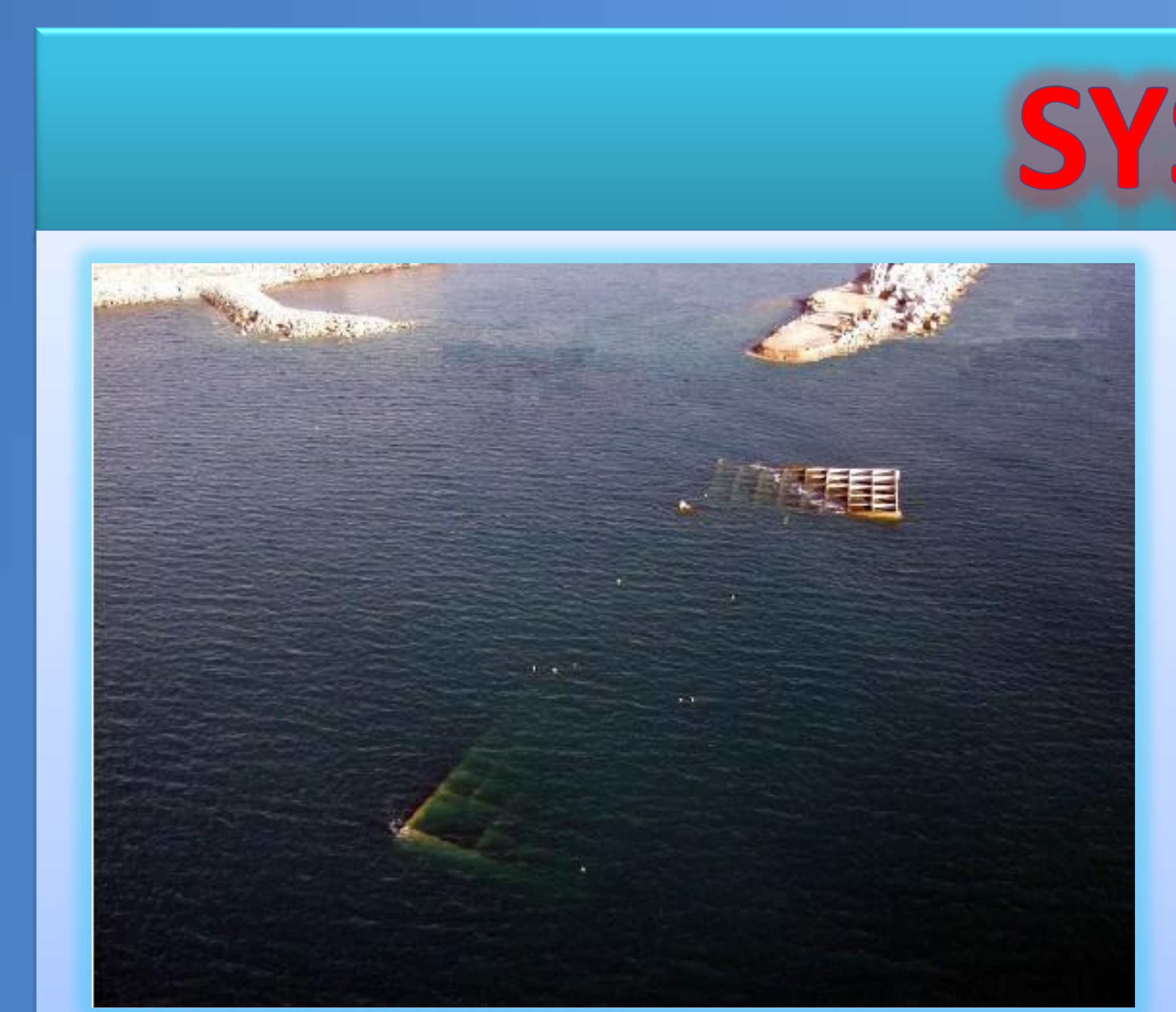

Figure 1. Failed caissons.

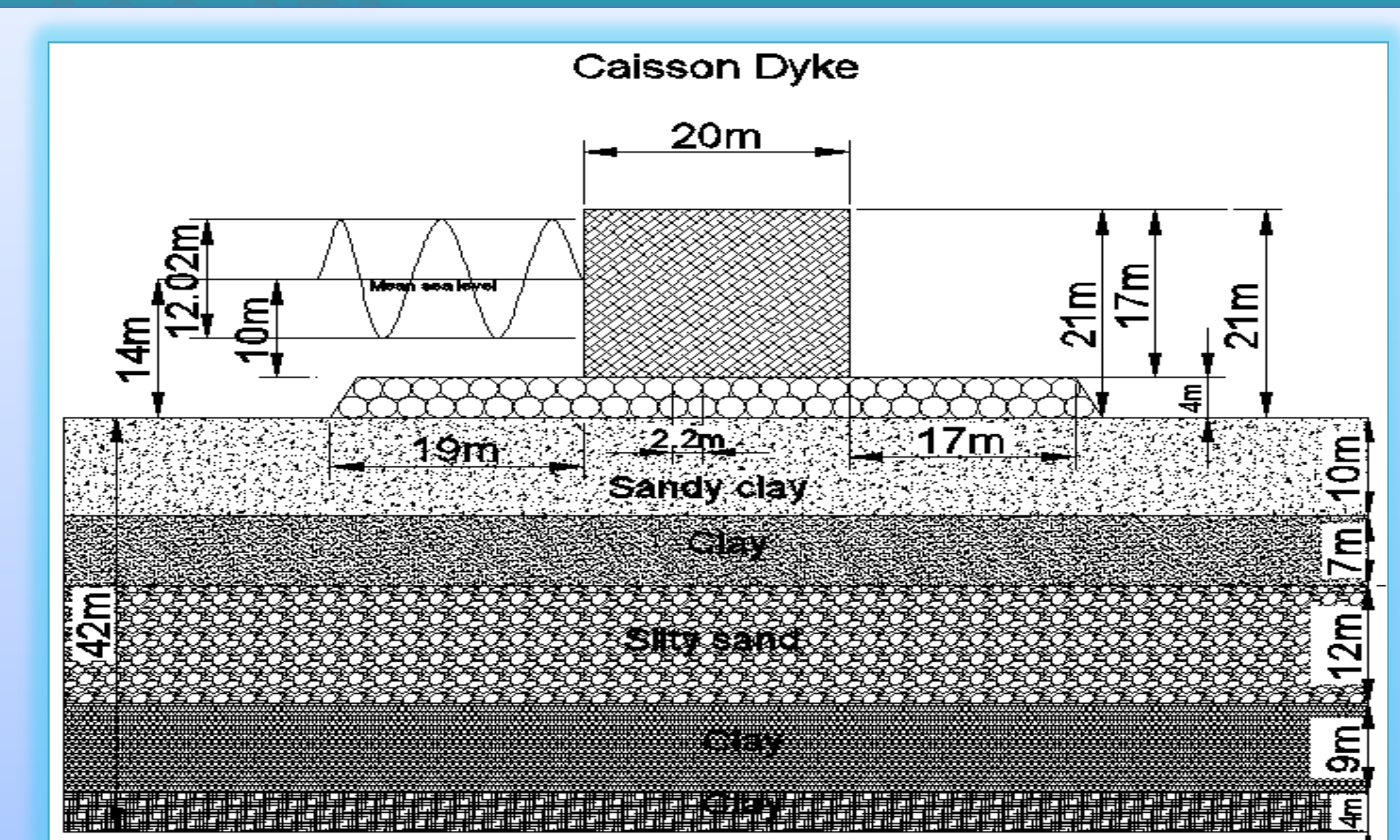

Figure 2. System, "Seabed-Structure-Wave.

STATIC SIMULATION

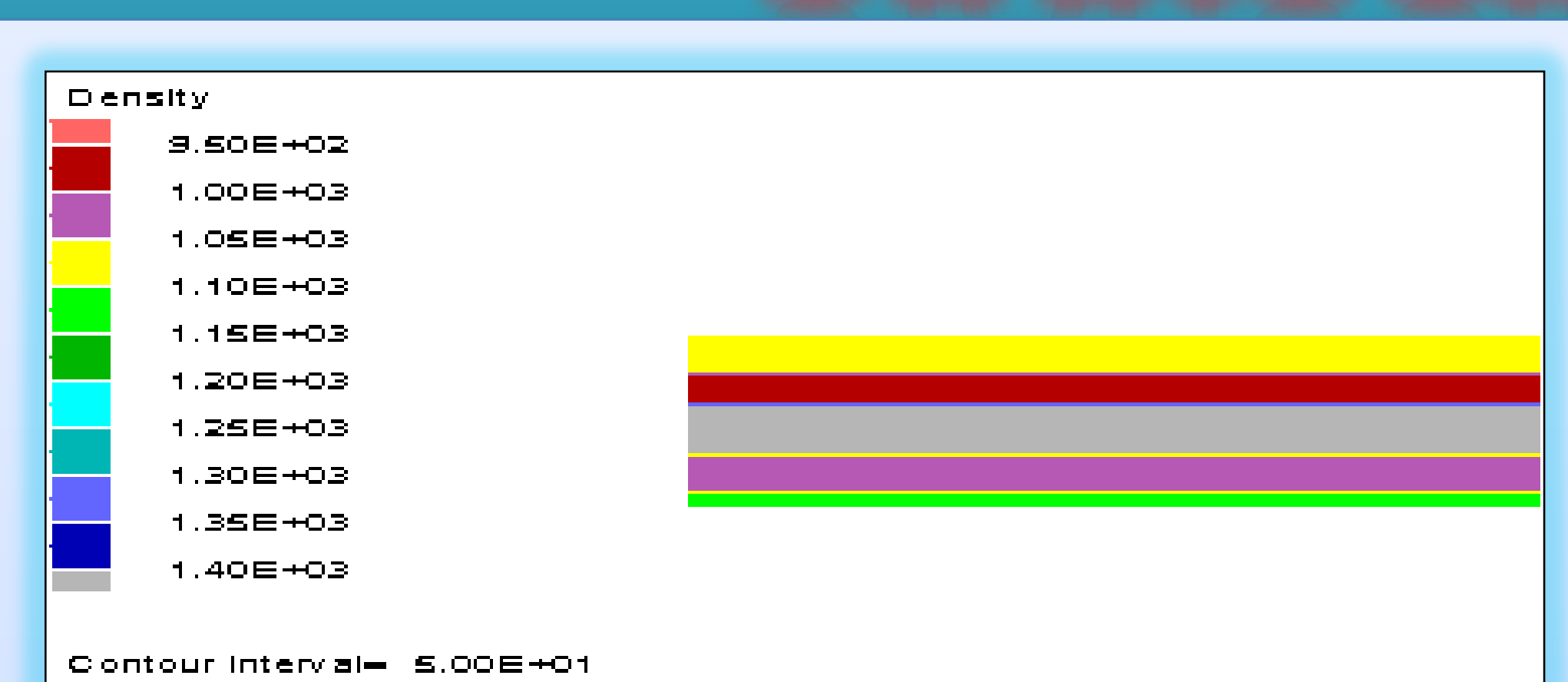

Figure 3. Seabed layers.

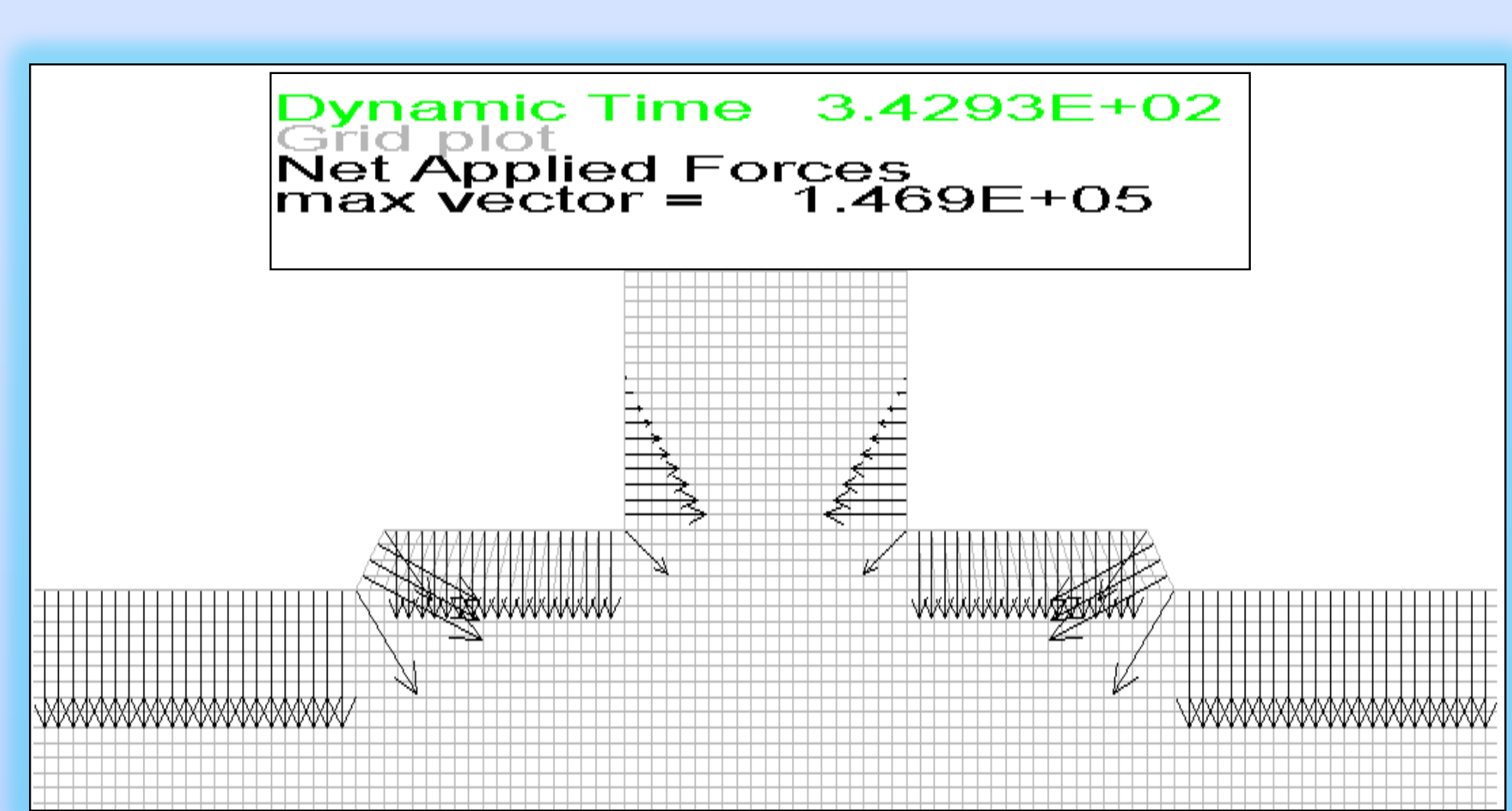

Figure 5. Hydrostatic loading.

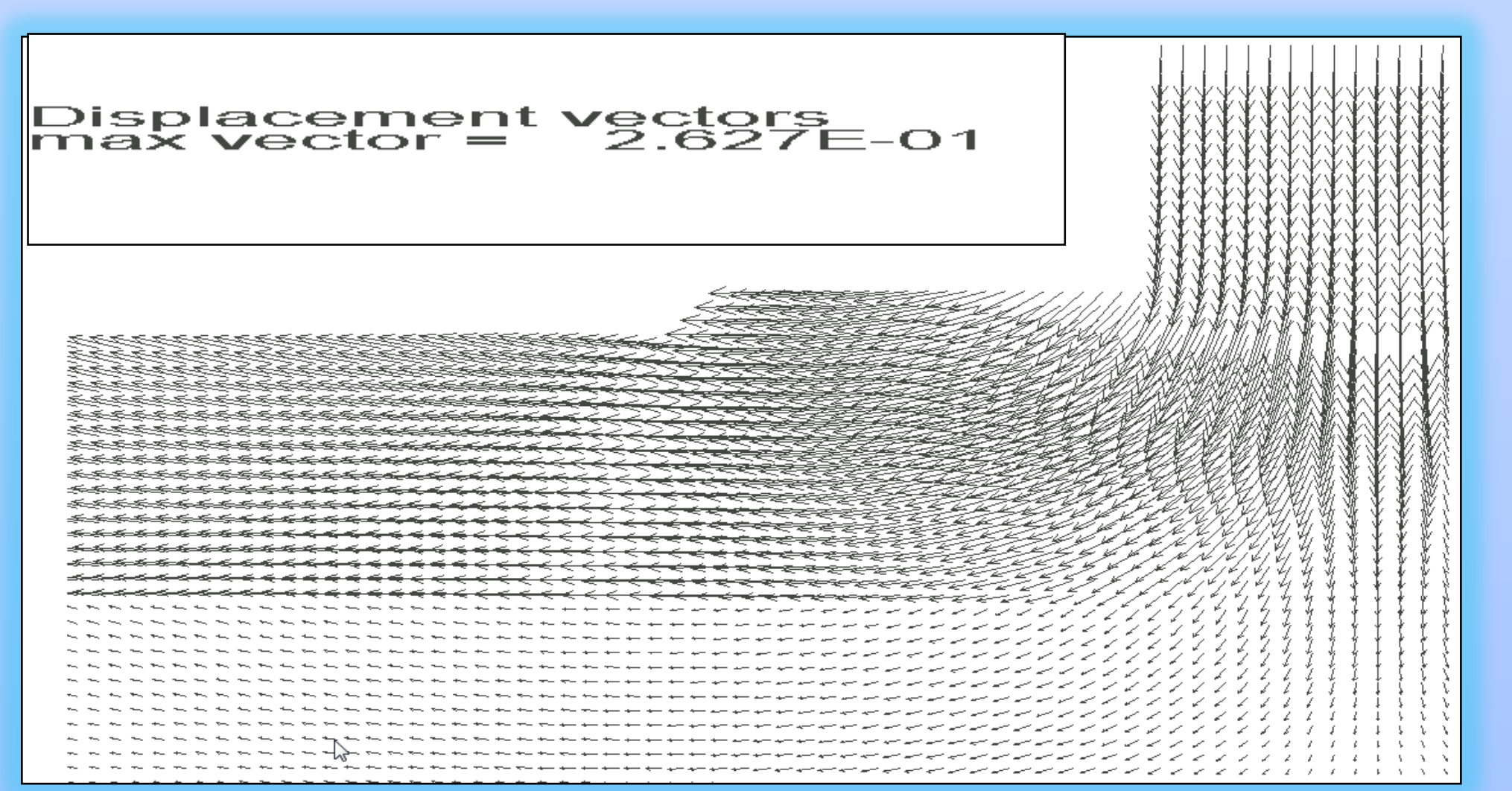

Figure 7. Total displacement.

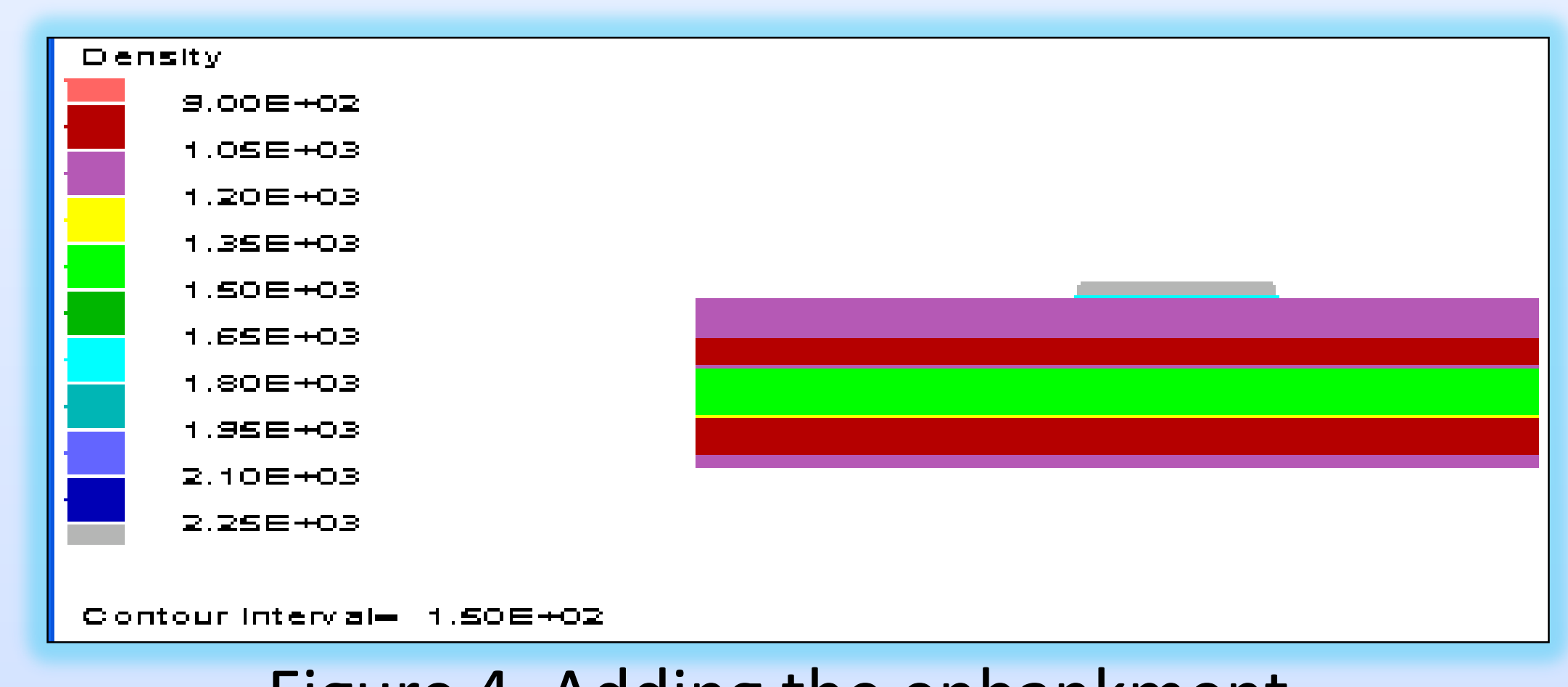

Figure 4. Adding the enbankment.

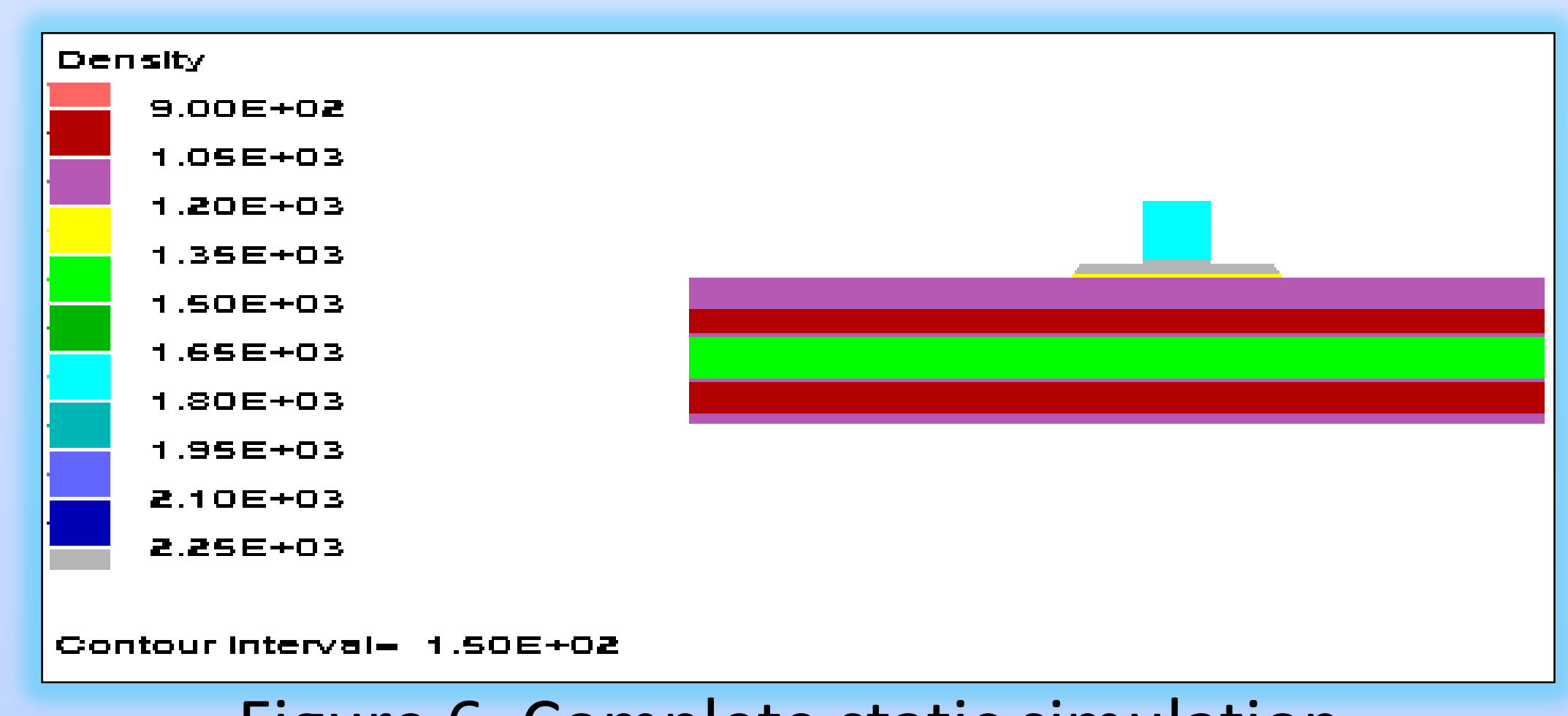

Figure 6. Complete static simulation

To simulate the caisson breakwater placement the principal construction stages were considered; these phases were simulated individually until the consolidation was achieved.

\section{DYNAMIC SIMULATION}
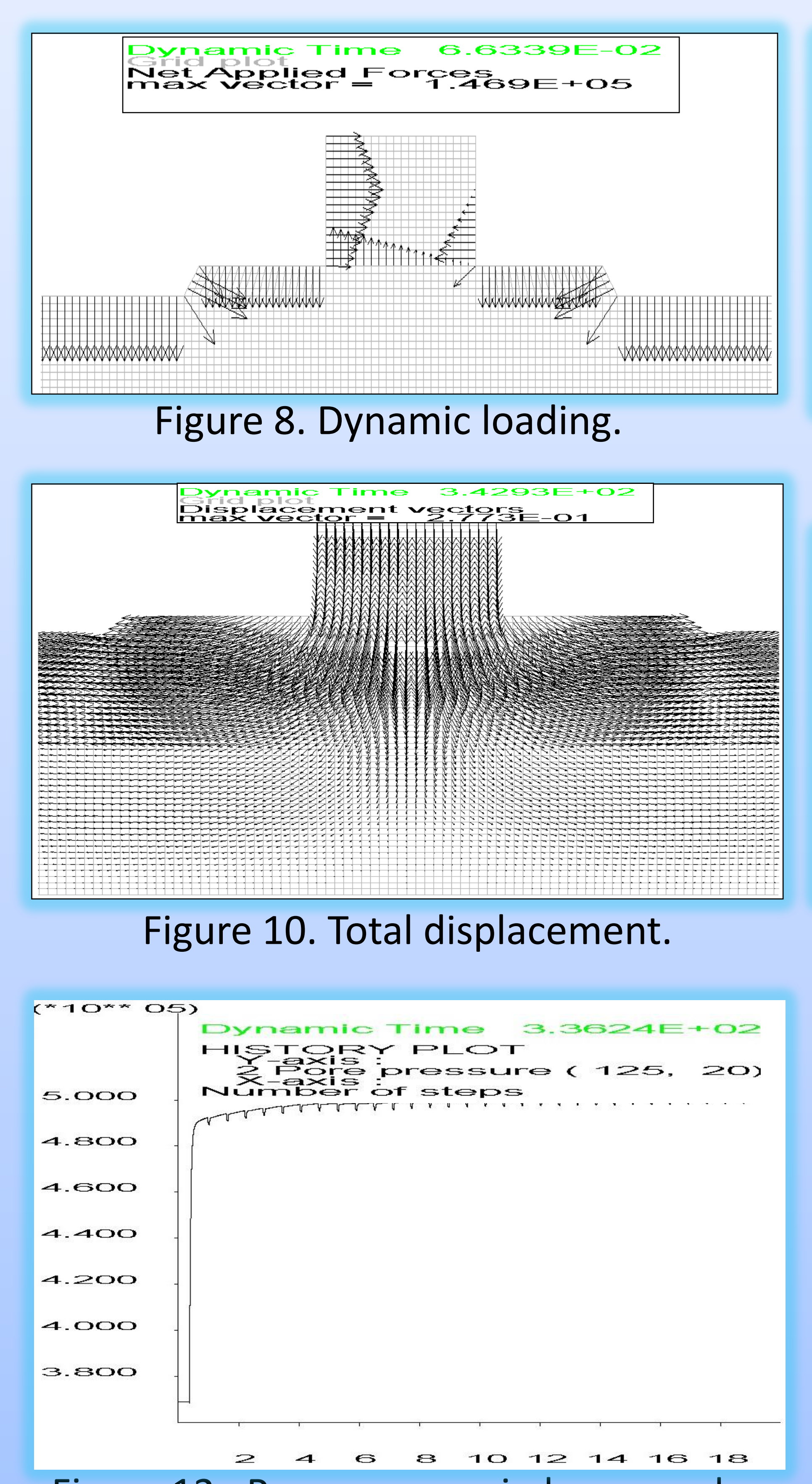

Figure 12. Pore pressure in layer sand.
Figure 10. Total displacement.

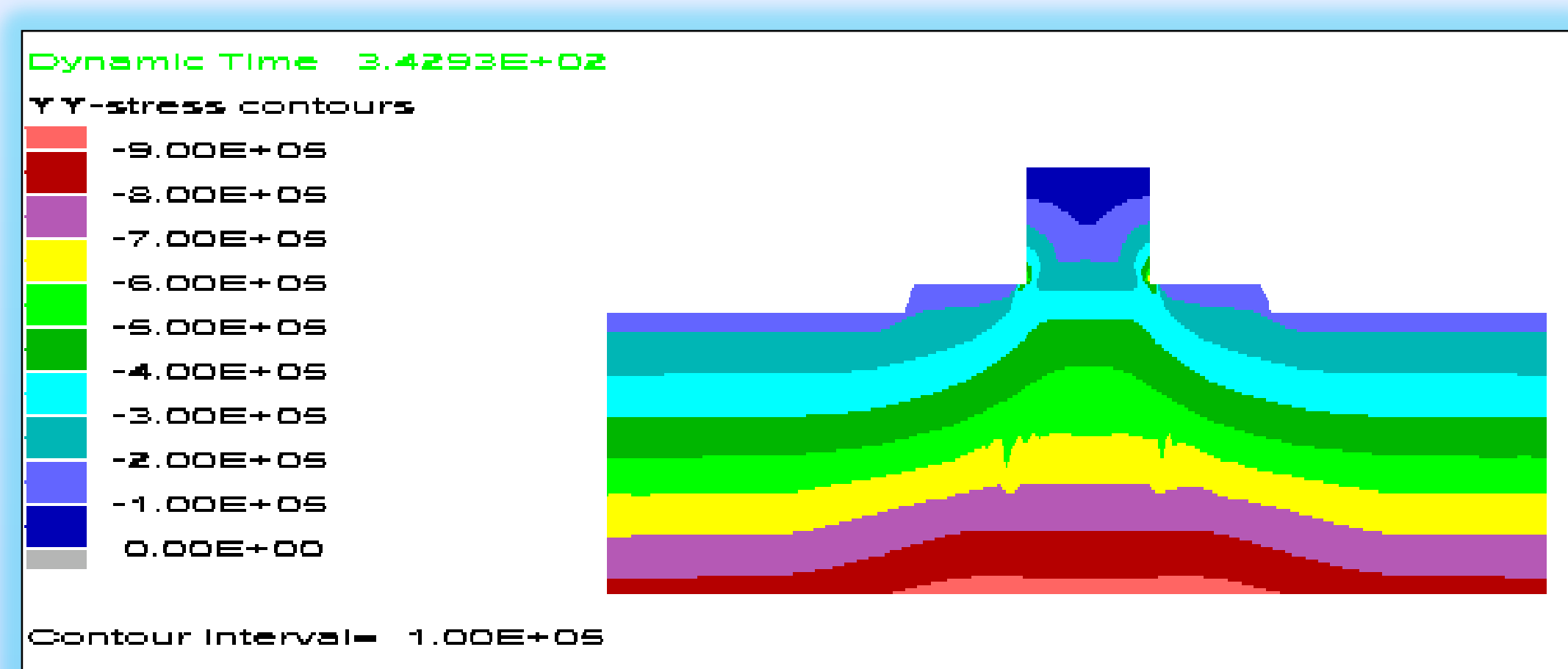

Figure 9. Vertical stresses after.

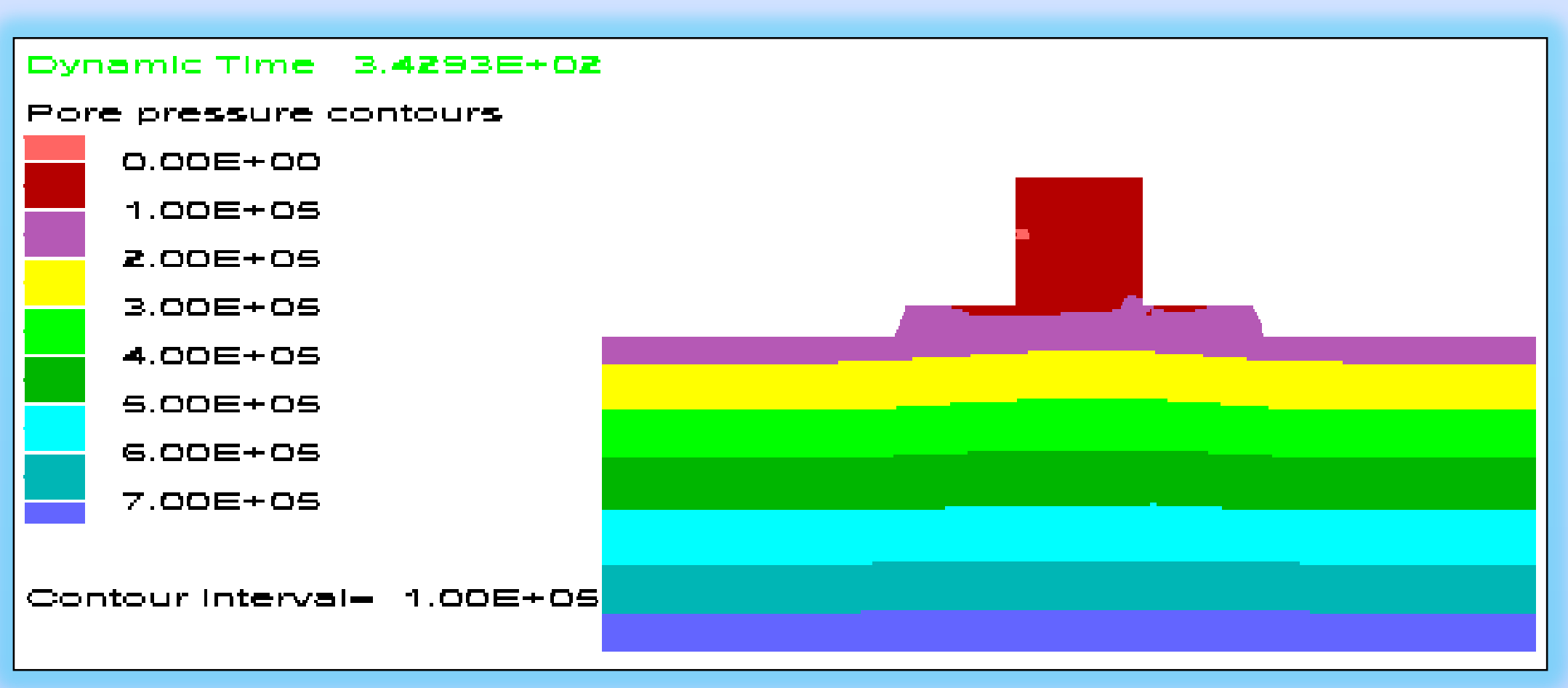

Figure 11. Pore Pressure.

- $\mathrm{Hmax}=12.02 \mathrm{~m}$

- Ts=11 s.

-Applied waves $=100$

-Wave pressures were applied $2 \mathrm{~s}$ in each cycle of 11s.

\section{Conclusions}

-The pore pressure after static simulation, has a gradual vertical distribution. - The degree of consolidation should be considered in the construction process, since this influences the seabed behavior.

-Dynamic simulation displays pore pressure increases, the variation in the sandy layer is less than in the top layer.

- The greatest increase in pore pressure occurred in the beginning of the wave action.

\section{References}

-Brebner, A. and Donnelly, D., 1962. "Laboratory Study of Rubble Foundations for Vertical Breakwaters." Proc. $8^{\text {th }}$ ICCE. New Mexico City, pp. 406-429.

-Goda, Y. 1973. "A New Method of Wave Pressure Calculation for the Design of Composite Breakwater." Rept. Port and Harbour Research Institute, Vol. 12

No. 3, pp. 31-70 (in Japanese); Proc. 14 th ICCE 1974, Copenhagen, Denmark, pp. 1702-1720.

-Leis, B., et al. 2007. Root Cause Analysis of the Usumacinta-KAB-101 Incident, Battelle's Energy Systems, Columbus, OH,USA.

-Puzrin, A.M., Alonso, E.E. and Pinyol, N. (2010), "Geomechanics of Failures", Springer, Amsterdam, pp. 87-146 pp.

-Ruiz, G., et al. 2008. Atlas del clima marítimo. XXIII Congreso Latinoamericano de Hidráulica. Cartagena de Indias, Colombia, septiembre 2008, 15 pp (CD). 